\title{
The Reliability of Metrologia 4.0 Data in the Industrial Technological Scenario: How This can Impact the Forms of Dimensional Control in the Industry
}

\author{
Kathleen Cristina Silveira Cunha, Ramon Oliveira Borges dos Santos, Larissa Silva D'Avila, \\ Regina Elaine Santos Cabette, Wilson de Freitas Muniz, Pedro Henrique Colman Prado, Luiz \\ Felipe Freire Honorato, Mariana Ferreira Benessiuti Motta, Carlos Dolberth Jaeger, Joselito \\ Moreira Chagas, Giulliano Assis Sodero Boaventura, Renann Pereira Gama, Adriano Carlos \\ Moraes Rosa
}

\begin{abstract}
The evolution of the human being is constant, we are always in search of new technologies, methods and techniques in order to provide several improvements such as, cost reduction, increase in quality, reduction in the use of natural resources, improvement of the workforce, agility of consequently provide improvements in quality of life. With the advancement of technology we came to the so-called "Fourth Industrial Revolution" which aims to generate and obtain data in real time, with the aim of optimizing decision making, increasing quality, mass customization, cost reduction and traceability. In view of this new industrial scenario, some methods will undergo significant changes, such as the field of science and action for measurement, called Metrology, whose purpose of this article is to exemplify metrology 4.0, calibration procedure with the help of IoT, calibration certificates in metrology 4.0, reliability, guarantee and security of the generated data. In view of fact that the area of Metrology has always been highlighted by major innovations in its working methods, using instruments of highly accurate measurements, these instruments in most cases can be mechanical or electronic equipment, but they need to be correctly calibrated to perform the function that has been proposed with excellence. Thus highlights the importance for the industrial scenario today, where concepts of IoT, machine learning, data science, artificial intelligence and industrial automation are tools that all engineering professional should obtain thorough knowledge. Mainly professionals in the area of metrology, which can use these concepts and tools to ensure the standard and reliability of the calibration of the measuring instruments.
\end{abstract}

Index Terms - Metrologia 4.0, Dimensional, IOT, Fourth

Industrial Revolution

Kathleen Cristina Silveira Cunha, Department of Mechanical Engineering, University of Roseira - Faro, Roseira - Sp, Brazil.

Ramon Oliveira Borges dos Santos, Department of Mechanical Engineering, Salesian University of São Paulo - Unisal, Lorena - Sp, Brazil.

Larissa Silva D'Avila, Department of Electrical, Electronics and Computing Engineering, Salesian University of São Paulo - Unisal, Lorena Sp, Brazil.

Regina Elaine Santos Cabette, Department of Mechanical and Civil Engineering, Salesian University of São Paulo - Unisal, Lorena - Sp, Brazil.

Wilson de Freitas Muniz, Department of Mechanical Engineering, Salesian University of São Paulo - Unisal, Lorena - Sp, Brazil.

\section{INTRODUCTION}

In 2011, the concept known as "Industry 4.0 " or "Fourth Industrial Revolution" was conceived around the world, through an association of German companies, political representatives and academics that added the main technological innovations, whose main objective was to obtain technological innovation of leadership. [1]

Industrial Revolutions, as they are called, do not happen frequently. Since the beginning of mankind, there were four industrial revolutions, the most recent being the fourth identified as such. The other three were identified only when they had already occurred, while the fourth is in full development. It is fundamental to all who work both in industry, as in any branch of activity, knowing this process and to prepare for the future that has already started.

The implementation of systems that can be used to locate people and objects in closed environments is one of the issues that are being discussed as one of the topics of the industry 4.0. [2]

This innovation in the industrial environment can impact on several aspects, encouraging the relationship environment between employees and companies, as it is always used and used easily when necessary, or time is a relevant factor in the industrial process, as well as industry 4.0. Since this parameter, a great example is the use of RFID in used parts, tools and machines used in a way that is more easily located or the product or batch allowed, in some cases in large batches are tracked via GPS.

Nowadays, this concept allows to unite the physical, digital and biological world, porpuse target the execution of intelligent factories with their modular structures, cyber-physical systems monitor physical processes and constantly communicate with each other and with man in time real, through the Internet of Things (IoT), information collected dynamically in the big data tool and stored in cloud computing. Transparency is provided throughout the production process, which leads to optimized and decentralized decision-making, according to studies $[3,4]$.

As a result of this revolution, some existing methods have undergone or will undergo several modifications to allow the generation and visualization of data in real time 
and, consequently, one of the most important methods is the field of science and action for measurement. Metrology, has been improved with the application of new techniques and innovations in sensors, as it is directly linked to technological development, purpose offer and contribute to the increase of productivity and competitiveness in the industry.

In the midst of the emergence of so many technologies and an unbridled growth of industrial and commercial needs, solutions are constantly being developed and implemented in the most diverse branches of business in order to provide an increase in sales and production. [2]

Industry 4.0 and the Internet of Things (IoT) are terms frequently encountered which are so concomitant to future production, labor and business. Both are closely interlinked with the increase of interconnectivity provided from IoT present in factories intelligent.

\section{THEORETICAL FOUNDATION}

\subsection{Metrology 4.0}

In the midst of the emergence of so many technologies and an unbridled growth of industrial and commercial needs, solutions are constantly being developed and implemented in the most diverse branches of business in order to provide an increase in sales and production.[2]

Metrology 4.0 is a technological innovation enhanced by industry 4.0, which, with the need for data generated in real time, promises to revolutionize the calibration process, in which conventional metrology required time and cost, as we will see in more detail below.

This innovation consists the ability to calibrate in real time, in addition to ensuring speed, integrity and intelligence of data in the calibration process, with the same quality. Although, to obtain this data, the use of IoT is essential, responsible for the integration of calibration systems, through IP and ERP protocols. In Figure 1, it is possible to see the transformations provided by metrology 4.0 .

Metrology as a science and action for the measurement, is one of the fields which offers great contribution for the increase of productivity and competitiveness in industry. With the advent of Internet call of things, Industry 4.0 and the growth in number of calibrations, a new challenge if evidence within the factories. The Metrology 4.0 brings the integration between patterns of calibration, calibration system and other systems can generate innovative actions and solutions. The results will be increasingly more collaborative in the decision making process between adjust, only calibrate or replacing an instrument in calibration.

The Metrology 4.0 bring the elevation of hardware and software affordable, making reliable calibration and productive in instrumentation and consequently within the industry. Assist the teams for the continuous improvement of process controls and critical analysis. With the entry of an industrial plant of large, medium and small businesses to the fourth industrial revolution through the metrology.

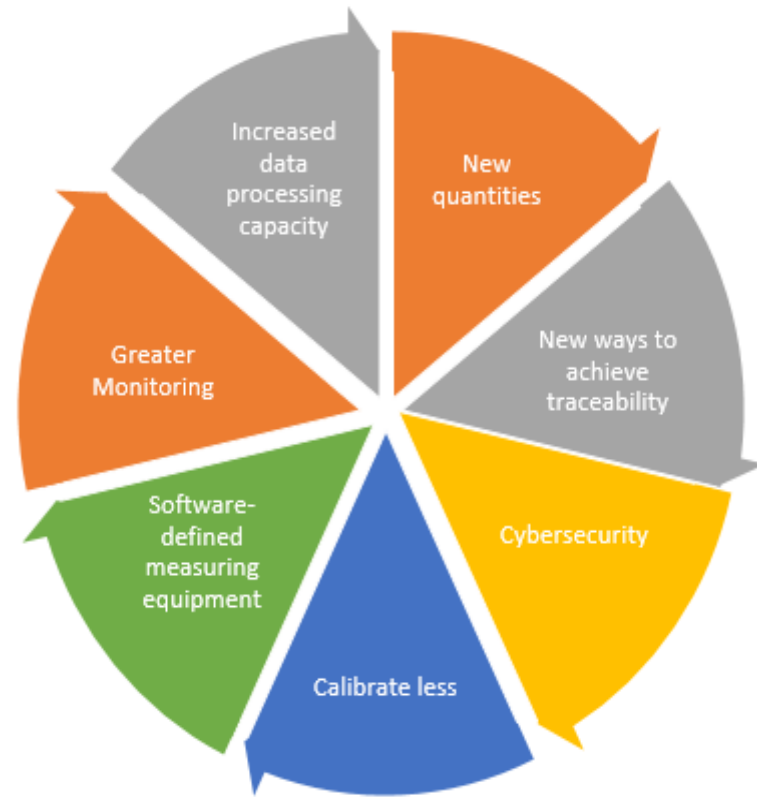

Figure 1. Transformations provided by metrology 4.0. [4]

Integration between calibration systems and calibration standards, will be able to generate innovative and customized actions, with increasingly collaborative conclusions in the decision-making process between adjusting, just calibrating or replacing a calibrated instrument.

\subsection{Procedure and Calibration Certificate 4.0}

Brazil inserted in an increasingly globalized scenario and international, thus, the industries need to ensure the quality of products offered and avoid manual activities that may compromise the integrity and productivity of work.

The calibration by the conventional method was demanding high time and cost for companies, opening up space for the Metrology 4.0 which ensures speed, data integrity and intelligence in calibration process, and especially the quality as the main characteristic of the measurement process.

The calibration procedure in metrology 4.0 is different from the conventional procedure, where the instrument needed to be removed from its environment, sent to the calibration laboratories (certified and accredited), and returned to the owner to be implemented again. And it was subject to several adversities as seen in Table 1.

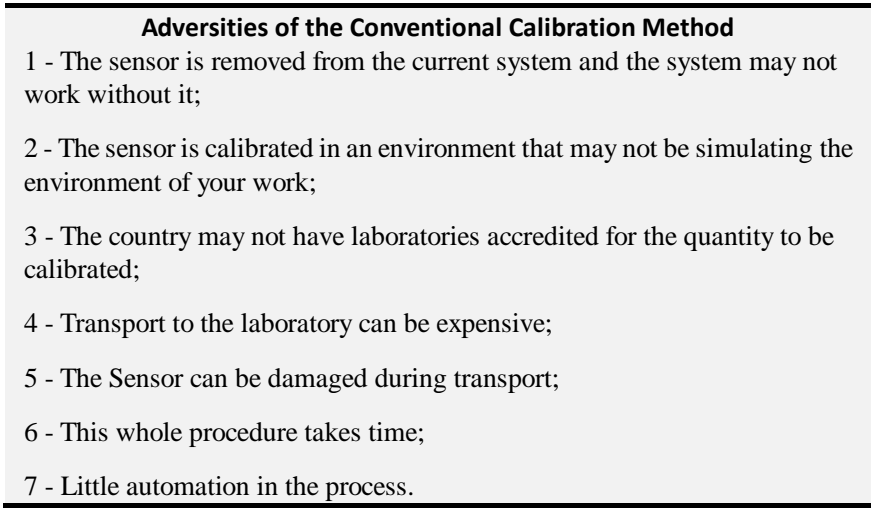

Table 1. Adversity of the Conventional Calibration Method. [8]

Through this new process, the calibration will move to the 
instrument that solves this complex procedure. Through an open service order of the company's ERP, containing the location of the instrument, the order number and all activities, the professional moves to the communication stage of the calibration software with the calibrator.

The technician enters the field with this device, performs the calibration procedure, which must meet the requirements of the standard ABNT NBR ISO / IEC 17025: 2017 - General requirements for the competence of the testing and calibration laboratories and the recommendations of the OMM Meteorological Organization Worldwide and has access to the process tolerance limits. At the end of the calibration process, a document is generated called a calibration certificate or calibration report, which must also be in accordance with ABNT NBR ISO / IEC 17025: 2017. [5]

Among the advantages of these procedures, we highlight the reduction of data entry errors, time reduction and consequently productivity gains. Figure 2 below exemplifies the operational model of calibration 4.0 using the Isoplan system.

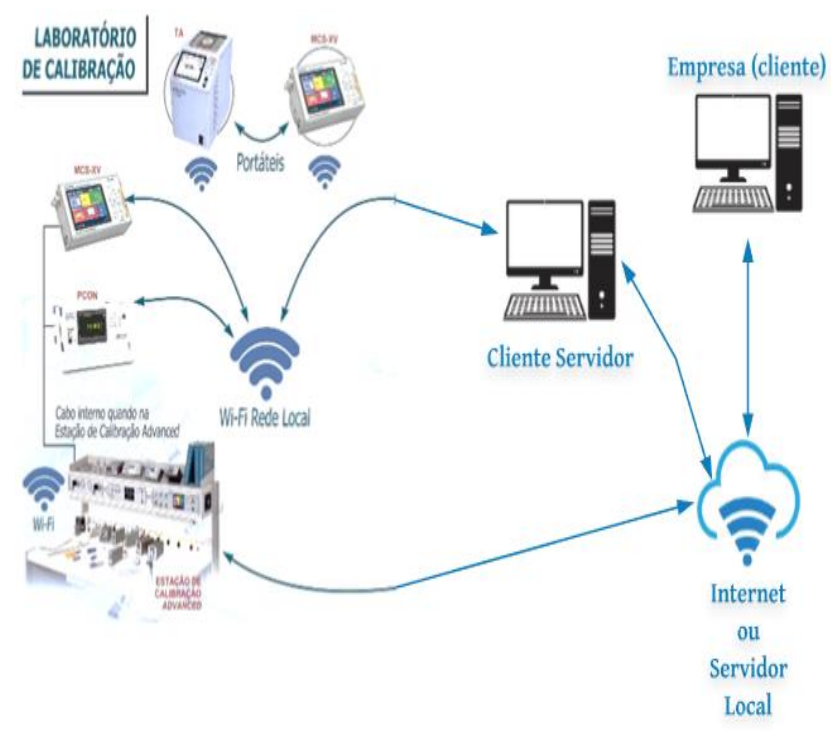

Figure 2. Calibration procedure 4.0. [8]

\subsection{Data Generated in Calibration 4.0}

The data generated in the term "4.0" is fully virtualized, that is, all information is collected dynamically to facilitate decision-making based on the big data tool, is stored in cloud computing and, as previously seen, the information is obtained through the IoT interface and corresponding software and protocols. [6]

There are software and hardware integrations that need to be made from the point of the communication interface with the sensor, to carry the data through structures of data communication networks, short and long distance, in addition to being necessary perform integration with servers and database. [7]

An advantage of using this virtual method is, without a doubt, the total reduction of paper flow in metrology 4.0, since the calibrator stores: the procedure, standard calibration certificate, work instructions. Figure 3 shows the process for obtaining 4.0 calibration.

The result arising from the calibration for the Industry 4.0 will not compose only the issuance of a certificate, but rather an input of knowledge to the productive system in which it is inserted, which comes a responsibility of decision-making processes.

The calibration laboratories must adapt to this new way of transmitting knowledge. The companies providing service in the field of metrology should assume that this knowledge is essential for the success of their productions guaranteeing the quality of production line.

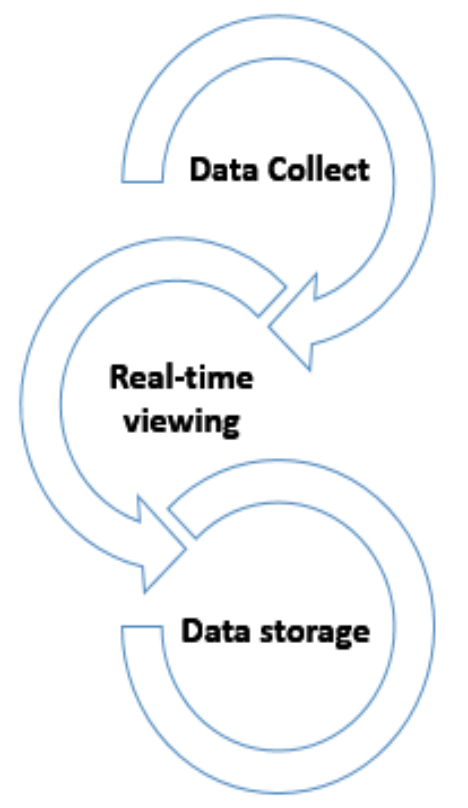

Figure 3. Control and Instrumentation. [7]

The future is intended to meet the demand for lead information directly to the local decision making, providing the metrological data for users of the equipment, for direct application in the production environment or field work, in real time.

With all the technology and data available, intelligent and adaptive strategies of quality will be implemented, so the company earns a profit, productivity time, avoids wastage of raw material, uniformity in the batch produced and avoiding non-compliances. Assisting the manager of production and quality to create strategies to make decisions relevant to a good driving the production line

\section{RESULTS}

Currently the computers has become efficient in everyday life of some people and organizations, with the advance of technology and the development of new programming languages, saw if necessary application of this concept in scientific research, to decrease the chances of errors in complex calculations. [8]

The reliability of the data is directly linked to the acceptance criterion, which are the parameters that serve as a reference to verify whether the instrument is suitable for use. They can also be defined as rejection criteria, where the allowed errors determine the adjustment in the instrument or the suitability for use. It is recommended to develop criteria to evaluate the results of the verification and calibration activities. [9]

The references to these criteria are based on an uninterrupted and documented calibration chain, each 
contributing to the measurement uncertainty. Figure 4 illustrates the hierarchy of metrological patterns disseminated internationally.

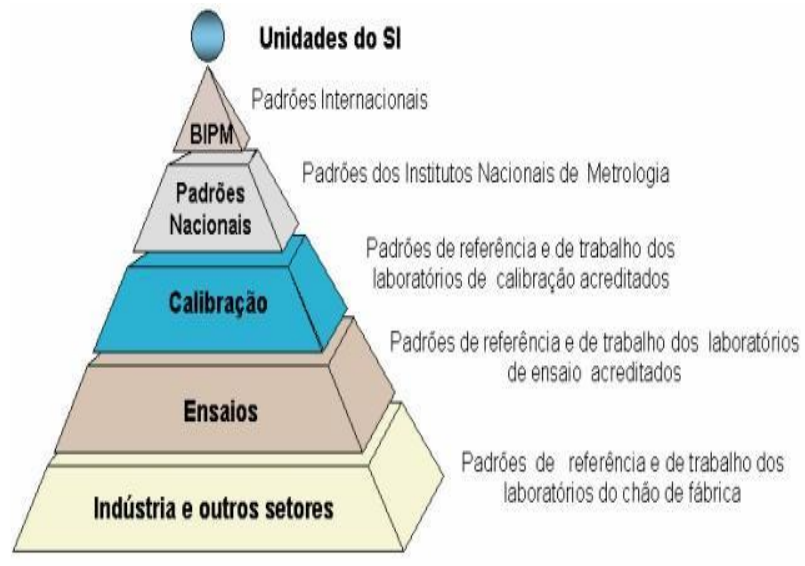

Figure 4. Metrology Standards Hierarchy. [10]

It is worth noting that the data obtained through metrology 4.0 when being sent to cloud computing must be implemented in the virtual security systems, ensuring that the measurement data is not accessed or modified by unauthorized persons. It is also important to have traceability throughout the communication structure until reaching the cloud and at the end of the data usage. In the area of information security, there are standards that guide the procedures to be applied, one of which is ABNT NBR ISO / IEC 27002. [7]

When companies seek to observe your production system, purpose see possibilities, realize the potential of lucrative opportunities exist through the insertion of technological innovations. [11]

\section{CONCLUSION}

With the researches carried out, it is possible to observe that metrology 4.0 has numerous advantages over conventional metrology, in which a smaller number of calibrations stands out, due to the new industrial model that requires generation and obtaining of data in real time. However, there are still several challenges, such as the security of the generated data, the creation of new sensors, qualified professionals in metrology 4.0 and the low percentage of companies that operate with the concept of industry 4.0 in the country. Metrology 4.0 revolutionized the measurement and calibration method. Within a few years, it will be present in the national and international industrial scene, where large international and multinational companies have used this technology to constantly improve their production processes, guaranteeing a high performance industrial process, reducing essential waste, such as time and raw materials. Raw materials essential to all production processes of excellence. The Metrology 4.0 shows a great performance in industrial plants that is introduced, presenting the user with the correct results, it makes an excellent tool to be used in academic and professional, reducing the chances of errors is becoming increasingly relevant in the industrial process.

\section{REFERENCES}

[1] KAGERMANN et al. (2011) "Industrie 4.0: Mit dem Internert der Dinge auf dem Weg zur 4". Industriellen Revolution. VDI nachrichten, vol. 13 , no. 1 , pp 228-243.

[2] RANDI, W. H.; BALDO, R. G. (2019). Analysis of the Techniques and Technologies for Indoor Location. Sodebras Magazine, v. 14, n.165, p.50-56. Doi:dx.doi.org/10.29367/issn.1809-3957.14.2019.165.50.

[3] KAGERMANN et al. (2013) 'Recommendations for implementing the strategic initiative Industrie 4.0: Final report of the industrie 4.0'. Working Group, Acatech - National Academy of Science and Engineering.

[4] SOUZA, R. S. L. (2020) 'Metrology 4.0 Division Metrology in Information Technology and Telecommunications'. INMETRO.

[5] ALBERTAZZI, G. Jr., SOUZA, A. R., (2018) 'Fundamentals of Scientific and Industrial Metrology', edition 2.

[6] ALMEIDA, P. S. (2019) 'Industry 4.0 - Basic Principles, Applicability and Implementation in the Industrial Area'. São Paulo, 2019.

[7] METROLOGY 4.0 A NEW MEASURE, Control and Instrumentation, $21, \mathrm{n}^{\circ} 240,2018$.

[8] SANTOS, R. O. B.; MUNIZ, W. F. Computational Tool That Performs Calculations of Linear Systems Theorem Cramer. Exact Sciences Journal, (2018). Vol. 24, no. 2, p. 29-38. Available in: <http://revistas.unitau.br/ojs/index.php/exatas/article/view/2759/1860>

[9] CUNHA, K. C. S, et al. (2019) 'Logistics for the Calibration of a Meteorological Station', 10 th Brazilian Metrology Congress, 2019, Florianópolis - SC. Metrology.

[10] INMETRO. (2012) 'Quality and Technology / Instituto Português da Qualidade. International Metrology Vocabulary: fundamental and general concepts and associated terms (VIM 2012)' - JCGM 200: 2012. 1st Luso-Brazilian Edition. Rio de Janeiro.

[11] CAMPOS, A. F.; WETLER, J. P.; FERNANDES, S. M. (2019). Green Economy In The Steel Industry: An Application (IM) Possible? Sodebras Magazine, v. 14, n.162, p.04-10.DOI: doi.org/10.29367/issn.1809-3957.14.2019.162.4.

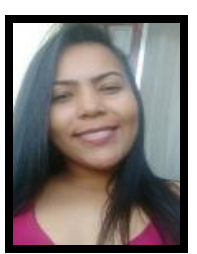

Kathleen Cristina Silveira Cunha. Graduate student in Mechanical Engineering from the University of Roseira, currently researching on the graduation of energy systems and automation and industry 4.0. Participated in several Brazilian national congresses, recently attended the Brazilian Metrology congress where he presented his work.

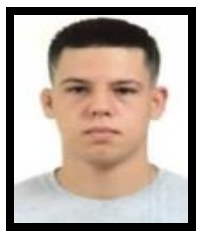

Ramon Oliveira Borges dos Santos. Graduate student in Mechanical Engineering from the Salesian University of São Paulo, currently researching on graduation in energy systems and control systems and automation and rotation of artificial satellites. I am currently a researcher for scientific initiation by CNPq National Council for Scientific and Technological Development, an agency that fosters Brazilian national research, the name of the research grant is PIBIC/UNISAL project number 801194/2018-0. During graduation participating in the Celeritas research project, where students develop innovative technologies through renewable energies for application in automobiles, homes and industries, for more information

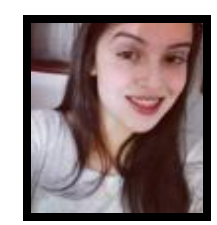

Larissa Silva D'Avila. Electrical Engineering from the University Salesian of São Paulo. I am currently working in the industrial maintenance sector. As a student researcher obtained a Technological Initiation scholarship - BITSAL, financed by University Salesian of São Paulo, researching "DEVELOPMENT OF A REMOTE MONITORING SYSTEM FOR HEART SIGNS WITH WEB INTERFACE". I am currently interested in pursuing my studies at master level in the field of health, biomedical and electronic engineering and computing. As a student researcher, I have research interests from health topics such as cardiology development, heartbeat, assistive engineering, engineering with social projects, in the area of electrical and electronic engineering the following research themes stand out, Electric Cars, Energy Efficiency, Renewable Energy, Embedded Electronics, Arduino Microcontrollers, Control Systems, Maintenance Management and Electrical Machines applied -............ $1 \mathrm{n}$ 


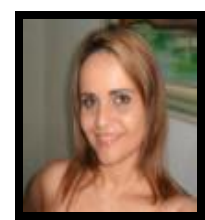

Regina Elaine Santos Cabette. $\mathrm{PhD}$ in Space Engineering and Technology by Inpe - National Institute for Space Research (2006), post-doctorate in Space Engineering and Technology by the National Institute for Space Research (2007) and post-doctorate in Computing and Applied Mathematics by the National Institute for Space Research (2011). She is a professor at University Salesian of São Paulo, Lorena city. Coordinator of mechanical and civil engineering courses. She worked as a collaborating researcher on the thematic project of FAPESP - Artificial Satellite Dynamics. Professor coordinator Celeritas research project, where students develop innovative technologies through renewable energies for application in automobiles, homes and industries, for more information (https://www.facebook.com/unisalceleritas/).

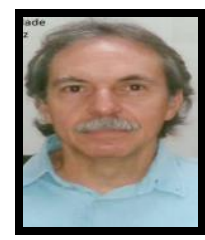

Wilson de Freitas Muniz. Graduated in Chemical Engineering from the University of Chemical Engineering in Lorena (1984), graduated in Physics from University State Paulista Júlio de Mesquita Filho (1995), Master in Space Sciences from the National Institute for Space Research (1993). He is currently a full professor University Salesian of São Paulo - UNISAL. Has experience in Statistics, with emphasis on Correlation and Regression, in the area of Combustion in the following subjects: swirlers, flame anchoring, lifting and blowout, flame holding and swirling flows

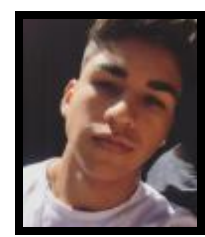

Pedro Henrique Colman Prado. Graduating student in mechanical engineering at University Salesian of São Paulo, he is a research student linked to the mechanical engineering department at University Salesian of São Paulo, his research interests are manufacturing processes, mechanical design, machining, renewable energy and industrial automation. I am currently working on a continuous improvement project in machining large parts, working directly in heavy mechanics sectors. During graduation participating in the Celeritas research project, where students develop innovative technologies through renewable energies for application in automobiles, homes and industries, for more information

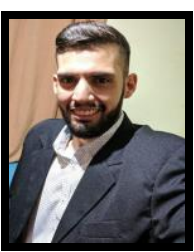

Luiz Felipe Freire Honorato. Graduating student in mechanical engineering at University Salesian of São Paulo, he is a research student linked to the mechanical engineering department at University Salesian of São Paulo, his research interests are manufacturing processes, mechanical design, machining, renewable energy and

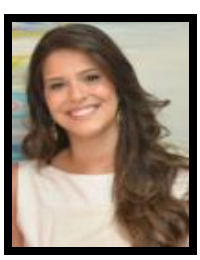

Mariana Ferreira Benessiuti Motta. $\mathrm{PhD}$ by the Postgraduate Program in Civil Engineering, in the area of Geotechnics, from the Pontifical Catholic University, PUC-Rio (2016), Master in Civil and Environmental Engineering, with an emphasis in Environmental Geotechnics from UNESP (2011) and a degree in Civil Engineering by UNESP (2008). He has experience in the area of Geotechnics, acting mainly on the following themes: soil mechanics, environmental geotechnics, unsaturated soils, laboratory and field tests, and slope stability.

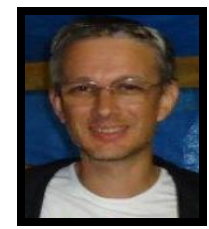

Carlos Dolberth Jaeger. Graduated in Electrical Engineering from the Federal University of Rio Grande do Sul (1991). Has experience in the area of Electrical Engineering, with emphasis on Electronics and Informatics, acting mainly in Research, Development and Operation of Measurement Systems, Control, Data Acquisition, Telecommunications. Main activities: test bench, laboratory, alternative energy, propeller development and testing.

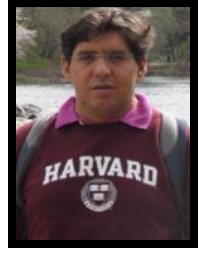

Joselito Moreira Chagas. Graduated in Electrical and Electronic Engineering from the University of Taubaté (1996).

Master in Manufacturing Engineering from Universidade Estadual Paulista Júlio Mesquita Filho. He is currently a specialist engineering professor at the University Salesian of São Paulo. Has experience in the area of Electrical and Mechanical Engineering, acting mainly on the following topics: maintenance, reliability, vibration analysis, asset management and bearings.

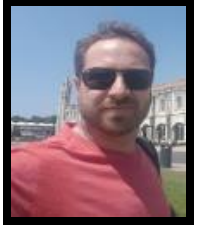

Giulliano Assis Sodero Boaventura. PhD student in Physics in the field of Orbital Dynamics and Planetology at University State Paulista Júlio Mesquita Filho. Master in Physics Teaching from University Federal Fluminense. Graduated in Physics from University State Paulista Júlio Mesquita Filho. He works as a substitute professor at University State Paulista Júlio Mesquita Filho in Experimental Physics and is part of the faculty of the University Salesian of São Paulo. Has experience in Astronomy, Particle Physics and Physics Teaching, with an emphasis on orbital dynamics and experimental constructions.

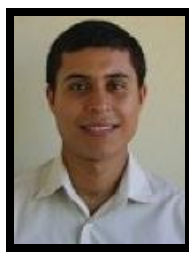

Renann Pereira Gama. Graduated in Materials Engineering from University State Paulista Júlio de Mesquita Filho (2011),

Master in Mechanical Engineering from Universty State Paulista Júlio de Mesquita Filho (2014) and PhD in Mechanical Engineering from University Estadual State Júlio de Mesquita Filho (2018). He is currently a professor at the University Salesian of São Paulo. Has experience in Materials and Metallurgical Engineering, with emphasis on Machining, acting on the following subjects: machining, nimonic 80a, roughness, superalloy and cutting tools.

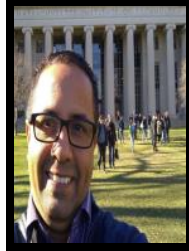

Adriano Carlos Moraes Rosa. PhD in Manufacturing Engineering from University Federal of Itajubá. Master in Management and Regional Development from University of Taubaté. Graduated in Office Automation and Secretariat from FATEC - Faculty of Technology of Guaratinguetá, has experience in the Education area, with emphasis on Administration and Logistics (Transport and Storage of Dangerous Products). He is a university professor since 2005 working at FATEC Guaratinguetá in the courses of Business Management / Management Processes, Logistics, Financial Management and Informatics. In all courses he teaches General Administration classes. 